\title{
Parental experiences and preferences as participants in pediatric research conducted in the emergency department
}

\author{
Antonia S. Stang, MDCM, MSc, MBA* ${ }^{\dagger \S}$; Stephen B. Freedman, MDCM, MSc ${ }^{* \S \uparrow ;}$; Angelo Mikrogianakis, \\ $\mathrm{MD}^{* \S}$; Graham C. Thompson, $\mathrm{MD}^{* \S}$; Janie Williamson, $\mathrm{RN}^{*}$; David W. Johnson, $\mathrm{MD}^{* \ddagger \S}$
}

\section{ABSTRACT}

Objective: To determine parental experiences and preferences regarding the conduct of pediatric research in an emergency department (ED) setting.

Methods: We conducted a cross-sectional study of parents of children ages $0-14$ years who visited the ED of a tertiary care children's hospital. Parents completed a Web-based survey designed to assess perceptions regarding: 1) background/ training of research personnel, 2) location and timing of research discussions, and 3) factors influencing their consent/ refusal decision.

Results: Parents totalling 339 were approached, and 227 (67\%) surveys were completed. Overall, 87\% (197/227; 95\% confidence interval $[\mathrm{CI}] 83,92)$ reported they would be comfortable being approached by a university student to discuss research. This proportion did not change when stratified by the child's gender, illness severity, or season of visit. Whereas only $37 \%(84 / 227 ; 95 \% \mathrm{Cl} 31,43)$ of respondents would be comfortable being approached in the waiting room, 68\% (154/ $227 ; 95 \% \mathrm{Cl} 62,75)$ would be comfortable if approached in a separate area of the main waiting room. The majority reported comfort with follow-up via email (83\%; 188/227; 95\% Cl 78, 88) or telephone (80\%; 182/227; $95 \% \mathrm{Cl} 75,85)$; only $51 \%$ (116/227; $95 \% \mathrm{Cl} 44,57)$ would be comfortable with a scheduled followup visit in the hospital. Participants identified potential complications or side effects as the most common reason for declining consent (69\%; 157/227; 95\% Cl 63, 75).

Conclusions: The majority of parents are comfortable being approached by trained university students, preferably in a separate area of an ED waiting room, and email and telephone follow-ups are preferred over a scheduled re-visit.

\section{RÉSUMÉ}

Objectif: L'étude visait à déterminer l'expérience et les préférences des parents en ce qui concerne les recherches menées en pédiatrie, au service des urgences (SU).

\begin{abstract}
Méthode: II s'agit d'une étude transversale, menée chez des parents d'enfants âgés de 0 à 14 ans, qui ont consulté un médecin au SU d'un hôpital de soins tertiaires pour enfants. Les parents ont rempli un questionnaire d'enquête en ligne, visant à évaluer leurs perceptions quant : 1) aux antécédents et à la formation du personnel de recherche; 2) au lieu et au moment de l'entretien sur la recherche; 3) aux facteurs qui ont incité les parents à accepter ou à refuser la demande de participation.

Résultats: On a demandé à 339 parents de participer à l'étude, et 227 d'entre eux (67\%) ont rempli le questionnaire en ligne. Dans I'ensemble, $87 \%$ des parents (197/227; IC à $95 \%$ : 83-92) ont indiqué qu'ils se sentiraient à l'aise s'ils étaient abordés par un étudiant qui leur expliquerait la recherche, et cette proportion restait stable, que le facteur de stratification fût le sexe de l'enfant, la gravité de la maladie ou la saison. Tandis que $37 \%$ seulement des répondants (84/227; IC à $95 \%$ : 31-43) se sont dits à l'aise devant le fait d'être abordés dans la salle d'attente, $68 \%$ (154/227; IC à $95 \%$ : 62-75) ont indiqué qu'ils se sentiraient à l'aise s'ils étaient abordés dans un lieu isolé de la salle d'attente principale. La majorité des participants se sont déclarés à l'aise avec le suivi par courriel (83\%; 188/227; IC à $95 \%$ : 78-88) ou par téléphone (80 \%; 182/ 227; IC à $95 \%$ : 75-85), tandis que $51 \%$ (116/227; IC à $95 \%$ : 44-57) seulement se sont dits à l'aise avec le suivi par rendez-vous à I'hôpital. Les principaux motifs de refus invoqués par les participants étaient les complications possibles ou les effets indésirables (69 \%; 157/227; IC à $95 \%: 63-75)$.

Conclusions: La majorité des parents se sont déclarés à I'aise devant le fait d'être abordés par des étudiants formés, préfèrent les entretiens dans un lieu isolé de la salle d'attente au service des urgences, et aiment mieux le suivi par courriel ou par téléphone que par rendez-vous à l'hôpital.
\end{abstract}

Keywords: pediatrics, parental preferences, research

From the *Department of Pediatrics; †Department of Community Health Sciences; and ‡Department of Physiology and Pharmacology, University of Calgary, Calgary, AB; §Alberta Children's Hospital Research Institute, Calgary, AB; and the ISections of Pediatric Emergency Medicine and Gastroenterology, Alberta Children's Hospital, Calgary, AB.

Correspondence to: Dr. Antonia S. Stang, Alberta Children's Hospital, 2888 Shaganappi Trail NW, Calgary, AB T3B 6A8; Email: antonia. stang@albertahealthservices.ca 


\section{INTRODUCTION}

A growing body of literature supports the involvement of health care consumers in the design, prioritization, and dissemination of research and evidence-based medicine. ${ }^{1-11}$ The cited benefits of including consumers include improved quality, clinical relevance, and uptake of research evidence. ${ }^{5,9,11}$ A number of recent publications have focused specifically on identifying participant opinions and preferences with respect to various aspects of research design and conduct, including consent materials and procedures, ${ }^{7}$ various survey modalities, ${ }^{8}$ and data sharing and repositories in genomic studies. ${ }^{10,12}$ Understanding participant preferences is particularly important in research involving children due to the necessary involvement of parents in providing informed consent, and often their active involvement through follow-up, medication administration, or travel. ${ }^{13}$ However, none of the publications on participant preferences, ${ }^{7,8,10,12}$ or any included in a systematic review of consumer involvement in developing health care policy and research, ${ }^{9}$ included parents/guardians or pediatric research. As a result, data on parental preferences in the design and conduct of pediatric research are limited.

Most patients who are treated in academic acute care institutions initially present for care in an emergency department (ED). ${ }^{14}$ Consequently, a significant proportion of outcome focused research involving acutely ill and injured children occurs in EDs. Although prior studies have focused on the issue of waived informed consent in resuscitation research, ${ }^{15,16}$ there is a paucity of knowledge describing parental preferences and perceptions regarding the conduct of pediatric research specific to the ED environment.

Although all clinical research involves the need to balance limited funding with the time and human resource costs associated with enrolling children, ${ }^{13}$ this is particularly true in the ED setting. Patients and families visit EDs 24 hours per day, and it is difficult to predict when eligible patients will present. The ED is a stressful environment, there is limited time to consider the study being proposed, and there is usually no existing relationship between the eligible participant and the clinical or research teams. To address the cost implications of the aforementioned recruiting challenges, a number of institutions have designed programs that use highly trained undergraduate students to screen and enrol subjects into clinical research studies. ${ }^{17-20}$ Previous publications have documented the success of such programs using measures such as enrolment, retention, and academic productivity. ${ }^{17-20}$ However, parental comfort and perception of recruitment into clinical studies by such trainee programs remain unknown.

To address the gap in the existing literature with respect to participant experience and preferences with respect to the design and conduct of pediatric research in the ED setting, we designed a cross-sectional survey with the objective of assessing 1) comfort of parents and guardians being approached by trained university students and research nurses to discuss research for which their child may be eligible; 2) parental comfort with the location and timing of the approach; 3) options for research-related follow-up after discharge from the ED; and 4) factors that influence parents'/guardians' decision to participate in pediatric ED research.

\section{METHODS}

\section{Study design}

Because of the lack of research on participant preferences and experiences specific to the pediatric ED setting, we were unable to identify any previously validated measures or tools. As a result, we developed a cross-sectional survey using a published, systematic approach to survey design, development, testing, and administration. ${ }^{21}$ Item generation and reduction were based on a literature review, interviews with parents, and focus group sessions with the research team. The response format was based on prior research in the pediatric setting identified in our literature review, which used a four-point Likert scale (i.e., $1=$ strongly disagree, 2 = disagree, $3=$ agree, $4=$ strongly agree $)^{22}$ and binary (yes/no) responses. ${ }^{23}$ The survey also collected demographic information about the child visiting the ED and the parent, and their previous experience in clinical research. Face and content validity were assessed by a panel of local researchers $(n=8)$ with expertise in pediatric emergency medicine, clinical research, and survey design. The survey was pilot tested on a random sample of parents of children brought for ED care $(\mathrm{n}=15)$. Ethics approval was obtained from the Conjoint Health Research Ethics Board of the University of Calgary. 


\section{Study setting and population}

This study was conducted in the ED of a tertiary care children's hospital in Calgary, Alberta. The ED has an annual census of approximately 80,000 pediatric visits. The study population included a simple random sample (i.e., next available based on registration time) of parents/guardians of children ages $0-14$ years who presented between 0800 and 2400 hours. We excluded the parents/guardians of children who 1) required resuscitation; 2) were eligible for other concurrent research studies; 3) were unable to comprehend the English language consent form; and 4) were over 14 years of age and could qualify as mature minors and provide consent themselves according to provincial law and the consent policy of our health research ethics board.

\section{Study protocol}

Potentially eligible parent/guardian participants were identified, screened, and enrolled by volunteer research assistants (RAs). At the time of the study, our volunteer Pediatric Emergency Medicine Research Associate Program (PEMRAP) included 63 student volunteers who were mentored and supervised by a group of research nurses, coordinators, and physician investigators. The RAs were available to aid in screening and enrolling patients in the ED 16 hours per day, 7 days per week. As soon as the screening and consent were completed, the RAs provided participating parents/guardians with an iPad tablet upon which they could confidentially complete the survey using REDCap, a secure online database. ${ }^{24}$ RAs were blinded to all caregiver responses. The latter was achieved through the use of direct entry of responses into a tablet and the submission of responses to a secure server by the study participants.

\section{Outcomes}

The primary outcome was comfort of parents and guardians being approached by a trained university student to discuss a research study for which their child may be eligible. Secondary outcomes included parental/ guardian 1) comfort with being approached by a research nurse; 2) comfort with the location and timing of approach by research staff; 3) comfort with follow-up options; and 4) reasons for consenting or refusing to have their child participate in research.
Comfort regarding approach by university students and nurses, and location of approach, was assessed using a four-point Likert-type scale $(1=$ strongly disagree, $2=$ disagree, $3=$ agree, $4=$ strongly agree). Questions regarding follow-up options and factors influencing participation decisions regarding research in a pediatric ED were structured to provide dichotomous responses. Factors previously identified as influencing parental decisions to participate in pediatric trials were also explored. ${ }^{22,23}$

\section{Sample size and analysis}

Study sample size was based on the primary outcome which was the proportion of respondents selecting 3 or 4 (agree or strongly agree) on a four-point Likert-type scale indicating comfort with being approached by an undergraduate student to discuss research for which their child might be eligible. In the absence of prior research on this outcome, we used the most conservative estimate for sample size calculation purposes (i.e., 50\%). Enrolling 200 patients would enable an assessment of the primary outcome with a margin of $+/-7 \%$. To account for seasonal variation in ED wait times and illnesses, a minimum of 50 patients were enrolled during each season (i.e., winter, spring, summer, and fall).

SPSS (Version 19.0; Chicago, IL) was used to analyse data. Continuous variables were described using means and standard deviations, and dichotomous variables using proportions with a $95 \%$ confidence interval (CI).

\section{RESULTS}

Participants were recruited between November 2013 and November 2014 (Figure 1). RAs approached 339 parents/guardians, and 227 (67\%) completed the study survey instrument. Because of our ethics agreement and local consent policies, we were unable to collect any information about non-participants, other than age and acuity (Canadian Triage and Acuity Scale [CTAS] category) of the child presenting to the ED, which did not vary between respondents (median CTAS 3 [interquartile range; IQR 1] and median age 5 [IQR 9]) and non-respondents (median CTAS 3 [IQR 1] and median age 5 [IQR 8]). Survey respondent median age was 37 years (IQR 11) (Table 1). Sixty-eight percent (154/227) of surveys were completed by the child's mother. 


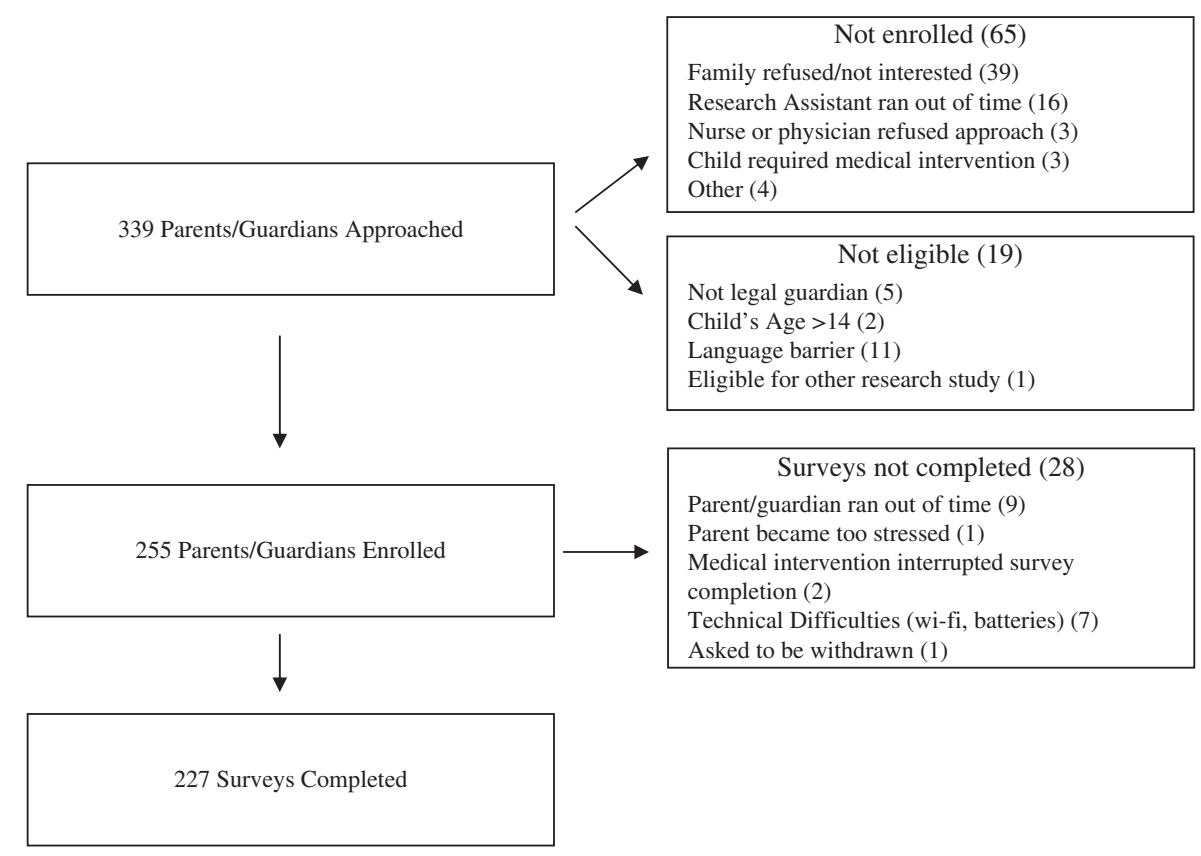

Figure 1. Flow Chart of Participant Enrollment.

Sixty-nine percent $(157 / 227)$ of respondents described themselves as Caucasian, and 81\% (186/227) indicated that they spoke English as the primary language at home. Over half of respondents (52\%, 118/227) reported a household income of $\geq \$ 80,000$, and $63 \%$ (144/227) had a college or graduate/professional degree. Twenty-five percent $(45 / 227)$ of respondents indicated that they had previously consented for their child's participation in research, and 28\% (64/227) had consented to participate in a research study themselves. With respect to acuity of the child visiting the ED, 69\% $(158 / 227)$ were in the urgent (CTAS 3$)^{25}$ and emergent (CTAS 2) triage categories.

\section{Primary outcome}

Eighty-seven percent (197/227; 95\% CI 83, 92) of respondents reported that they would be comfortable being approached by a trained university student for discussion regarding the participation of their child in a research study. Table 2 shows the primary outcome according to the demographic characteristics of survey respondents and children visiting the ED. Compared with parents/guardians who have not previously consented for their child's participation in a research study, those who had consented were somewhat more likely to report comfort with approach by trained university students. There was no meaningful difference in the primary outcome when stratified by the demographic characteristics of the respondents, including gender, ethnicity, household income, or education level. Similarly, there was no difference in the primary outcome when stratified by the characteristics of the child visiting the $\mathrm{ED}$, including the child's illness severity or season of visit.

\section{Secondary outcomes}

Ninety-one percent (207/227; 95\% CI 87, 95) of respondents reported that they would be comfortable being approached by a trained research nurse. Thirty percent $(68 / 227$; $95 \%$ CI 24,36$)$ of study participants indicated that they would be comfortable being approached by research staff prior to the triage nurse evaluation to discuss participation in a research study. An additional 36\% (i.e., 66\%, 150/227; 95\% CI 60, 72) indicated that they would be comfortable being approached after the triage nurse assessment but before being seen by a physician.

Thirty-seven percent $(84 / 227 ; 95 \%$ CI 31,43$)$ of respondents were comfortable being approached in the main waiting room; $68 \%(154 / 227$; $95 \%$ CI 62,75$)$ were comfortable being approached in a separate area of the main waiting room (i.e., a more private area). With respect to follow-up options, $83 \%$ (188/227; $95 \%$ CI 78 , 88 ) of respondents were comfortable with email, and $80 \%$ 
Table 1. Demographic characteristics of the survey respondents (parents/guardians) and children visiting the emergency department

\begin{tabular}{|c|c|c|}
\hline SURVEY RESPONDENTS & Median & Interquartile range (IOR) \\
\hline \multirow[t]{2}{*}{ Age } & 37 & 11 \\
\hline & Number & Proportion $(N=227$ ) \\
\hline \multicolumn{3}{|l|}{ Gender } \\
\hline Male & 66 & $29 \%$ \\
\hline \multicolumn{3}{|l|}{ Relationship to child } \\
\hline Mother & 154 & $68 \%$ \\
\hline Father & 66 & $29 \%$ \\
\hline Legal guardian & 1 & $0 \%$ \\
\hline Other/don't know/decline to answer/missing & 6 & $3 \%$ \\
\hline \multicolumn{3}{|l|}{ Ethnicity } \\
\hline Caucasian & 157 & $69 \%$ \\
\hline Asian & 35 & $15 \%$ \\
\hline First Nations/Aboriginal & 11 & $5 \%$ \\
\hline Black & 6 & $3 \%$ \\
\hline Other/don't know/decline to answer/missing & 18 & $8 \%$ \\
\hline \multicolumn{3}{|l|}{ Primary language at home } \\
\hline English & 186 & $81 \%$ \\
\hline French & 1 & $0 \%$ \\
\hline Other & 35 & $15 \%$ \\
\hline Don't know/decline to answer/missing & 5 & $2 \%$ \\
\hline \multicolumn{3}{|l|}{ Citizenship } \\
\hline Canadian by birth & 157 & $69 \%$ \\
\hline Canadian by naturalization & 25 & $11 \%$ \\
\hline Landed immigrant & 29 & $13 \%$ \\
\hline Visitor to Canada & 7 & $3 \%$ \\
\hline Other/don't know/decline to answer/missing & 9 & $4 \%$ \\
\hline \multicolumn{3}{|l|}{ Household income } \\
\hline$<\$ 10,000$ & 4 & $2 \%$ \\
\hline$\$ 10,000$ to $<\$ 40,000$ & 16 & $7 \%$ \\
\hline$\$ 40,000$ to $<\$ 80,000$ & 42 & $18 \%$ \\
\hline$\$ 80,000$ to $<\$ 130,000$ & 54 & $24 \%$ \\
\hline$>\$ 130,000$ & 64 & $28 \%$ \\
\hline Other/don't know/decline to answer/missing & 48 & $21 \%$ \\
\hline \multicolumn{3}{|l|}{ Highest level of education } \\
\hline Grade school & 1 & $.5 \%$ \\
\hline High school & 34 & $15 \%$ \\
\hline Some college & 33 & $15 \%$ \\
\hline College degree & 62 & $27 \%$ \\
\hline Graduate or professional degree & 82 & $36 \%$ \\
\hline Vocational school & 4 & $2 \%$ \\
\hline Other/don't know/decline to answer/missing & 12 & $5 \%$ \\
\hline \multicolumn{3}{|l|}{ Marital status } \\
\hline Single & 21 & $9 \%$ \\
\hline Married & 162 & $71 \%$ \\
\hline Divorced & 8 & $3 \%$ \\
\hline Common law & 27 & $12 \%$ \\
\hline Other/don't know/decline to answer/missing & 10 & $5 \%$ \\
\hline \multicolumn{3}{|l|}{ Hours of Internet access per day } \\
\hline None & 4 & $2 \%$ \\
\hline 1 to 6 hours & 72 & $31 \%$ \\
\hline 7 to 12 hours & 24 & $10 \%$ \\
\hline
\end{tabular}




\begin{tabular}{|c|c|c|}
\hline SURVEY RESPONDENTS & Median & Interquartile range (IQR) \\
\hline \multirow[t]{2}{*}{ Age } & 37 & 11 \\
\hline & Number & Proportion $(N=227)$ \\
\hline 13 to 18 hours & 6 & $3 \%$ \\
\hline 19 to 24 hours & 112 & $49 \%$ \\
\hline Other/don't know/decline to answer/missing & 10 & $5 \%$ \\
\hline \multicolumn{3}{|l|}{ Prior consent to research } \\
\hline For your child & 45 & $25 \%$ \\
\hline For yourself & 64 & $28 \%$ \\
\hline CHILDREN & Median & Interquartile range (IQR) \\
\hline \multirow[t]{2}{*}{ Age } & 5 & 9 \\
\hline & Number & Proportion \\
\hline \multicolumn{3}{|l|}{ Acuity of presentation ${ }^{25}$} \\
\hline CTAS 1 (requires resuscitation) & 2 & $1 \%$ \\
\hline CTAS 2 (emergent) & 45 & $20 \%$ \\
\hline CTAS 3 (urgent) & 113 & $50 \%$ \\
\hline CTAS 4 (less urgent) & 49 & $22 \%$ \\
\hline CTAS 5 (non-urgent) & 17 & $7 \%$ \\
\hline Unknown/not charted & 1 & $0 \%$ \\
\hline \multicolumn{3}{|l|}{ Primary/usual care provider } \\
\hline Emergency department & 33 & $15 \%$ \\
\hline Walk-in clinic & 16 & $7 \%$ \\
\hline Family doctor & 149 & $64 \%$ \\
\hline Pediatrician & 20 & $9 \%$ \\
\hline Other/don't know/decline to answer/missing & 10 & $5 \%$ \\
\hline Admitted to hospital on this visit & 27 & $12 \%$ \\
\hline \multicolumn{3}{|l|}{ Season of visit } \\
\hline Fall & 55 & $24 \%$ \\
\hline Winter & 56 & $25 \%$ \\
\hline Spring & 58 & $25 \%$ \\
\hline Summer & 58 & $25 \%$ \\
\hline
\end{tabular}

(182/227; 95\% CI 75, 85) were comfortable with a scheduled phone call, compared to 51\% (116/227; 95\% CI 44, 57) comfortable with a scheduled visit to the hospital or ED (Table 3). The most common reason that parents/guardians report that they would consent for their child to participate in a research study is that it would possibly benefit other children (91\%; 207/227; 95\% CI 87,95 ) (Table 4). Concern about possible complications or side effects is the most common reason that respondents would decline consent (69\%; 157/227; 95\% CI 63, 75) (Table 5).

\section{DISCUSSION}

The majority of parents/guardians of children brought for ED care are comfortable with being approached by a trained university student to discuss research for which their child may be eligible. Comfort with approach by a trained university student study was somewhat greater amongst caregivers of children who had previously participated in research, but it did not vary based on other demographic characteristics of the parents/guardians or the children themselves. Caregivers expressed greater comfort with being approached regarding a research study after triage has been completed, and they expressed a preference for having the discussion in a private area.

Prior publications have documented advantages associated with the use of undergraduate RA programs to assist in the conduct of clinical research in the ED setting. Advantages for researchers include cost savings, efficient and effective subject identification and enrollment, and increased academic productivity ${ }^{17-20}$; for 


\begin{tabular}{|c|c|c|c|}
\hline SURVEY RESPONDENTS & Numerator & Denominator & Proportion \\
\hline \multicolumn{4}{|l|}{ Gender } \\
\hline Male & 55 & 66 & $83 \%$ \\
\hline Female & 139 & 156 & $89 \%$ \\
\hline \multicolumn{4}{|l|}{ Ethnicity } \\
\hline Caucasian & 137 & 157 & $87 \%$ \\
\hline Asian & 29 & 35 & $83 \%$ \\
\hline First Nations/Aboriginal & 11 & 11 & $100 \%$ \\
\hline Black & 6 & 6 & $100 \%$ \\
\hline \multicolumn{4}{|l|}{ Household income } \\
\hline$<\$ 10,000$ & 4 & 4 & $100 \%$ \\
\hline$\$ 10,000$ to $<\$ 40,000$ & 15 & 15 & $100 \%$ \\
\hline$\$ 40,000$ to $<\$ 80,000$ & 37 & 42 & $88 \%$ \\
\hline$\$ 80,000$ to $<\$ 130,000$ & 47 & 54 & $87 \%$ \\
\hline$>\$ 130,000$ & 59 & 64 & $92 \%$ \\
\hline \multicolumn{4}{|l|}{ Highest level of education } \\
\hline Grade school & 1 & 1 & $100 \%$ \\
\hline High school & 33 & 34 & $97 \%$ \\
\hline Some college & 31 & 33 & $94 \%$ \\
\hline College degree & 55 & 62 & $89 \%$ \\
\hline Graduate or professional degree & 68 & 81 & $84 \%$ \\
\hline Vocational school & 2 & 4 & $50 \%$ \\
\hline \multicolumn{4}{|c|}{ Prior consent to research for your child } \\
\hline Yes & 43 & 44 & $98 \%$ \\
\hline No & 144 & 171 & $84 \%$ \\
\hline \multicolumn{4}{|l|}{ CHILDREN } \\
\hline & Numerator & Denominator & Proportion \\
\hline \multicolumn{4}{|l|}{ Gender } \\
\hline Male & 114 & 131 & $87 \%$ \\
\hline Female & 80 & 91 & $88 \%$ \\
\hline \multicolumn{4}{|l|}{ Acuity of presentation ${ }^{25}$} \\
\hline CTAS 1 (requires resuscitation) & 1 & 2 & $50 \%$ \\
\hline CTAS 2 (emergent) & 37 & 45 & $82 \%$ \\
\hline CTAS 3 (urgent) & 100 & 109 & $92 \%$ \\
\hline CTAS 4 (less urgent) & 40 & 48 & $83 \%$ \\
\hline CTAS 5 (non-urgent) & 15 & 17 & $88 \%$ \\
\hline \multicolumn{4}{|l|}{ Season of visit } \\
\hline Fall & 46 & 54 & $85 \%$ \\
\hline Winter & 50 & 55 & $91 \%$ \\
\hline Spring & 47 & 56 & $84 \%$ \\
\hline Summer & 51 & 57 & $89 \%$ \\
\hline
\end{tabular}

students, they include exposure to clinical medicine, training and experience in research, and mentorship from clinicians and researchers. ${ }^{17-20}$ However, no prior publications provide any information from the perspective of the patient or the parent. Our results provide evidence of parental comfort, across a wide spectrum of demographic characteristics, with being approached by trained undergraduate RAs, thereby providing further validation for this cost-effective and innovative research model.

The rationale for patient involvement is the importance of ensuring that patients' views are incorporated into the design and conduct of research. ${ }^{1}$ Recent research focused on the families of children receiving treatment $\left(6 \%\right.$ in the ED) in a tertiary care hospital ${ }^{26}$ reported that only $26 \%$ respondents had been invited to 


\begin{tabular}{|c|c|c|c|c|}
\hline $\begin{array}{l}\text { If my child were a participant in a } \\
\text { research project that requires follow- } \\
\text { up, I would be comfortable: }\end{array}$ & $\%$ yes $(n)$ & $\begin{array}{c}95 \% \\
\text { Confidence interval }\end{array}$ & $\begin{array}{l}\text { If yes, how many } \\
\text { times? }(\%)\end{array}$ & If yes, for how long of a time period? \\
\hline Being followed up via email & $83 \%(188)$ & $78 \%$ to $88 \%$ & $\begin{array}{l}1 \text { or } 2 \text { times }(55 \%) \\
3 \text { to } 5 \text { times }(27 \%) \\
>5 \text { times }(17 \%)\end{array}$ & $\begin{array}{l}\leq 1 \text { week }(25 \%) \\
>1 \text { week to }<1 \text { month }(18 \%) \\
>1 \text { month to }<3 \text { months }(28 \%) \\
>3 \text { months to }<6 \text { months }(29 \%)\end{array}$ \\
\hline $\begin{array}{l}\text { Being followed up with a } \\
\text { scheduled phone call from } \\
\text { research personnel }\end{array}$ & $80 \%(182)$ & $75 \%$ to $85 \%$ & $\begin{array}{l}1 \text { or } 2 \text { times }(62 \%) \\
3 \text { to } 5 \text { times }(26 \%) \\
>5 \text { times }(11 \%)\end{array}$ & $\begin{array}{l}\leq 1 \text { week }(24 \%) \\
>1 \text { week to }<1 \text { month }(31 \%) \\
>1 \text { month to }<3 \text { months }(18 \%) \\
>3 \text { months to }<6 \text { months }(27 \%)\end{array}$ \\
\hline $\begin{array}{l}\text { Being followed up with a } \\
\text { scheduled visit from research } \\
\text { personnel to my home }\end{array}$ & $60 \%(136)$ & $53 \%$ to $66 \%$ & $\begin{array}{l}1 \text { or } 2 \text { times }(60 \%) \\
3 \text { to } 5 \text { times }(29 \%) \\
>5 \text { times }(11 \%)\end{array}$ & $\begin{array}{l}\leq 1 \text { week }(18 \%) \\
>1 \text { week to }<1 \text { month }(31 \%) \\
>1 \text { month to }<3 \text { months }(19 \%) \\
>3 \text { months to }<6 \text { months }(32 \%)\end{array}$ \\
\hline $\begin{array}{l}\text { Being followed up with a } \\
\text { scheduled visit to the hospital } \\
\text { or emergency department }\end{array}$ & $51 \%(116)$ & $44 \%$ to $57 \%$ & $\begin{array}{l}1 \text { or } 2 \text { times }(79 \%) \\
3 \text { to } 5 \text { times }(13 \%) \\
>5 \text { times }(7 \%)\end{array}$ & $\begin{array}{l}\leq 1 \text { week }(32 \%) \\
>1 \text { week to }<1 \text { month }(19 \%) \\
>1 \text { month to }<3 \text { months }(26 \%) \\
>3 \text { months to }<6 \text { months }(22 \%)\end{array}$ \\
\hline
\end{tabular}

participate in research. The majority $(87 \%)$ of those who indicated they had been approached stated that they had in fact consented; $65 \%$ of participating families reported that their experience was a positive one. Our work differs in that it is focused on the ED setting, and it explores parent/guardian comfort and preferences with respect to research design and elements that have not previously been explored. In addition, we provide the evidence that parents/guardians are comfortable with being approached by both trained undergraduate students and research nurses. We also provide insightful preferences regarding the optimal timing of approach (i.e., after triage) and location (i.e., in a private location) and follow-up modality (email). These findings are particularly relevant given the increasing volumes of patients seen in the ED setting, and the resultant pressure to efficiently assess patients, for clinical and research purposes.

In keeping with prior studies conducted in a pediatric asthma clinic, and as part of an infant vaccine trial in primary care physician's offices, ${ }^{1,23}$ we found that learning more about the disease and helping medical knowledge were identified as factors influencing the decision to participate. We also similarly found that the relationship with staff and the belief that the child's illness/disease is serious are important factors in parental consent. The infant vaccine trial ${ }^{23}$ identified concerns about an extra immunization and not wanting their child to be in a "study" as the most common reasons for refusal to consent. Our results show that concerns about complications, side effects, and procedures are the top reasons that parents would withhold consent in the ED setting. This knowledge provides valuable insight on key information that must be clearly addressed during the consent process. In contrast to the vaccine trial, ${ }^{23}$ only a small proportion of parents (19\%) whom we surveyed reported not wanting their child to be in a study as a reason to refuse consent. Another key difference was our finding that $50 \%$ (compared with $5 \%$ in the vaccine trial) ${ }^{23}$ of parents indicated that they would decline consent for their child's participation in a study because they are too busy. These findings highlight the need for ED researchers to minimize time demands on busy parents and families.

A growing body of research supports the involvement of health care consumers in health research, including evidence of improved research quality, clinical relevance, and uptake. ${ }^{1-11}$ Recent work has focused on identifying participant preferences with respect to research design and conduct. ${ }^{7,8,10,11}$ For example, a recent publication demonstrated that participant characteristics impacted survey mode preference (regular mail, website, telephone) and that participants were more likely to complete a survey in their stated preferred modality. ${ }^{8}$ These findings highlight the importance of setting specific knowledge about research participants, 
Table 4. Reasons respondents would consent to having their child participate in a research study

\begin{tabular}{|c|c|c|}
\hline Reason & $\%$ Answering yes $(n)$ & $\begin{array}{c}\text { 95\% Confidence } \\
\text { interval }\end{array}$ \\
\hline It would possibly benefit other children. & $91 \%(n=207)$ & $87 \%$ to $95 \%$ \\
\hline It would help me learn more about my child's illness or disease. & $88 \%(n=200)$ & $84 \%$ to $92 \%$ \\
\hline It would help increase medical knowledge. & $87 \%(n=197)$ & $83 \%$ to $92 \%$ \\
\hline There is minimal risk to my child. & $84 \%(n=191)$ & $79 \%$ to $89 \%$ \\
\hline It would give us access to the newest drugs and/or best possible treatments. & $80 \%(n=182)$ & $75 \%$ to $85 \%$ \\
\hline The involvement of the pediatrician is important to me. & $80 \%(n=182)$ & $75 \%$ to $85 \%$ \\
\hline My child's illness/disease is serious. & $80 \%(n=182)$ & $74 \%$ to $85 \%$ \\
\hline The research team member who approached me was reassuring. & $79 \%(n=179)$ & $73 \%$ to $84 \%$ \\
\hline The relationship with the emergency department staff (nurses and doctors) is important to me. & $76 \%(n=173)$ & $70 \%$ to $81 \%$ \\
\hline More visits will mean better care for my child. & $75 \%(n=170)$ & $69 \%$ to $81 \%$ \\
\hline My child will receive more attention if he/she is in a study. & $59 \%(n=134)$ & $52 \%$ to $66 \%$ \\
\hline I would like the free study materials. & $38 \%(n=86)$ & $32 \%$ to $45 \%$ \\
\hline I would like to be associated with the research study. & $34 \%(n=77)$ & $28 \%$ to $40 \%$ \\
\hline The financial benefit is appealing. & $28 \%(n=64)$ & $22 \%$ to $34 \%$ \\
\hline My family/friends would want me to. & $27 \%(n=61)$ & $21 \%$ to $33 \%$ \\
\hline
\end{tabular}

Table 5. Reasons parents would decline consent to have their child participate in a research study

\begin{tabular}{|c|c|c|}
\hline Reason & $\%$ Answering yes (n) & $\begin{array}{c}\text { 95\% Confidence } \\
\text { interval }\end{array}$ \\
\hline I am worried about possible complications or side effects. & $69 \%(n=157)$ & $63 \%$ to $75 \%$ \\
\hline I am concerned about procedures (blood work, for example). & $52 \%(n=118)$ & $45 \%$ to $58 \%$ \\
\hline I am too busy. & $50 \%(n=114)$ & $43 \%$ to $56 \%$ \\
\hline I am concerned about the number of follow-ups. & $49 \%(n=111)$ & $42 \%$ to $56 \%$ \\
\hline I do not believe that my child's illness/disease is serious. & $29 \%(n=66)$ & $23 \%$ to $35 \%$ \\
\hline I do not want my child in a "study." & $19 \%(n=43)$ & $14 \%$ to $25 \%$ \\
\hline The study seems too complicated. & $19 \%(n=43)$ & $14 \%$ to $25 \%$ \\
\hline Other members of my family would not want me to allow my child to participate. & $10 \%(n=23)$ & $6 \%$ to $14 \%$ \\
\hline I do not agree with research due to philosophical reasons. & $9 \%(n=20)$ & $6 \%$ to $13 \%$ \\
\hline I do not agree with research due to religious reasons. & $7 \%(n=16)$ & $3 \%$ to $10 \%$ \\
\hline
\end{tabular}

and the need to design research that is aligned with participant preferences. Our study makes an important contribution to the existing research about consumer involvement in health care research by providing data on parental preferences and experiences with research specific to the pediatric ED setting. Data on parental preferences are particularly important given the integral role that parents play in pediatric research, including their active role in consent, participation, and follow-up. Similarly, data specific to the ED setting are required given the episodic nature of ED care, the high volumes of patients seen in the ED setting, and the lack of an existing relationship with care providers. Because of the complexities and costs associated with conducting research in the ED setting, a number of institutions use undergraduate students to enrol patients into research studies. Although prior work provides evidence of the benefits of such programs from the perspective of the researcher and the students, ${ }^{17-20}$ data on parental comfort and experience are lacking.

Our findings have a number of implications for researchers and research team members conducting studies involving children in the ED setting. The finding that the majority of parents are comfortable being approached by a trained university student provides further support for such programs, which have a number of previously documented benefits for the research team, including cost savings, increased recruiting efficiency, and academic productivity. ${ }^{17-20}$ Guidance on parental preferences with respect to the location and timing of approach, and the modality and duration of follow-up, will enable researchers to design and conduct studies that meet participant needs and potentially improve participation and follow-up rates. 
Knowledge about parental opinions regarding consent has the potential to improve the consent process by identifying key information that should be highlighted, including the contribution to medical knowledge and specifics about complications, side effects, and procedures. Similarly, information about consent specific to the ED setting, such as the importance of minimizing time demands on busy patients and families, has the potential to improve consent rates and research quality.

\section{LIMITATIONS}

A limitation of our study was the lack of a validated tool to measure parental comfort and preferences with respect to research in the acute care setting. An additional limitation was that respondents were approached for participation by undergraduate RAs, and parental comfort with students was one of the outcomes of interest. To minimize the impact of these limitations, we ensured that the survey used had face validity, was easy to complete, and that the RAs were blinded to all caregiver responses. In addition, parents were not aware of the background and training of the individual approaching them (i.e., whether the individual was a research nurse or a university student).

\section{CONCLUSION}

This study provides important guidance on parental comfort and preferences with respect to research conducted in an ED setting. The majority of parents/ guardians of children brought for ED care are comfortable with being approached by a trained university student to discuss research for which their child may be eligible. Caregivers expressed greater comfort with being approached regarding a research study after triage has been completed and in a private area, as well as a preference for email or telephone follow-up as compared to a scheduled visit to the hospital. Future work should focus on the experiences and preferences of children and youth in the conduct of research in the ED setting, and determine whether these differ between the parent and child participants.

Acknowledgments: This project was funded by a 2012 Innovation Award from the Department of Pediatrics, University of Calgary, and the Alberta Children's Hospital Foundation.

Competing interests: None declared.

\section{SUPPLEMENTARY MATERIAL}

To view supplementary material for this article, please visit http://dx.doi.org/10.1017/cem.2017.22

\section{REFERENCES}

1. Gooberman-Hill R, Burston A, Clark E, et al. Involving patients in research: considering good practice. Musculoskeletal Care 2013;11(4):187-90.

2. Lander J, Hainz T, Hirschberg I, et al. Current practice of public involvement activities in biomedical research and innovation: a systematic qualitative review. PLoS One 2014; 9(12):e113274.

3. Oliver S, Armes DG, Gyte G. Public involvement in setting a national research agenda: a mixed methods evaluation. Patient 2009;2(3):179-90.

4. Frank L, Forsythe L, Ellis L, et al. Conceptual and practical foundations of patient engagement in research at the patient-centered outcomes research institute. Qual Life Res 2015;24(5):1033-41.

5. Boote J, Telford R, Cooper C. Consumer involvement in health research: a review and research agenda. Health Policy 2002;61(2):213-36.

6. Crawford MJ, Rutter D, Manley C, et al. Systematic review of involving patients in the planning and development of health care. BM7 2002;325(7375):1263.

7. Henry J, Palmer BW, Palinkas L, et al. Reformed consent: adapting to new media and research participant preferences. IRB 2009;31(2):1-8.

8. Mlikotic R, Parker B, Rajapakshe R. Assessing the effects of participant preference and demographics in the usage of Web-based survey questionnaires by women attending screening mammography in British Columbia. $7 \mathrm{Med}$ Internet Res 2016;18(3): $\mathrm{e} 70$.

9. Nilsen ES, Myrhaug HT, Johansen M, et al. Methods of consumer involvement in developing healthcare policy and research, clinical practice guidelines and patient information material. Cochrane Database Syst Rev 2006;3:CD004563.

10. Trinidad SB, Fullerton SM, Ludman EJ, et al. Research ethics. Research practice and participant preferences: the growing gulf. Science 2011;331(6015):287-8.

11. Whitstock MT. Seeking evidence from medical research consumers as part of the medical research process could improve the uptake of research evidence. 7 Eval Clin Pract 2003;9(2):213-24.

12. Trinidad SB, Fullerton SM, Bares JM, et al. Genomic research and wide data sharing: views of prospective participants. Genet Med 2010;12(8):486-95.

13. Zylke JW, Rivara FP, Bauchner H. Challenges to excellence in child health research: call for papers. FAMA 2012; 308(10):1040-1.

14. Kocher KE, Dimick JB, Nallamothu BK. Changes in the source of unscheduled hospitalizations in the United States. Med Care 2013;51(8):689-98.

15. Baren JM, Anicetti JP, Ledesma S, et al. An approach to community consultation prior to initiating an emergency research study incorporating a waiver of informed consent. Acad Emerg Med 1999;6(12):1210-5. 
16. McClure KB, DeIorio NM, Gunnels MD, et al. Attitudes of emergency department patients and visitors regarding emergency exception from informed consent in resuscitation research, community consultation, and public notification. Acad Emerg Med 2003;10(4):352-9.

17. Davis DP, Poste JC, Kelly D. The UCSD Research Associate Program: a recipe for successfully integrating undergraduates with emergency medicine research. 7 Emerg Med 2005;28(1):89-93.

18. Hollander JE, Singer AJ. An innovative strategy for conducting clinical research: the academic associate program. Acad Emerg Med 2002;9(2):134-7.

19. Steadman PE, Crudden J, Naranian T, et al. The professional benefits for volunteer research assistants in a pediatric emergency department. I Emerg Med 2015; 48(3):287-93.

20. Steadman PE, Crudden J, Naranian T, et al. The effectiveness of a student volunteer program for research in a pediatric emergency department. 7 Emerg Med 2014; 48(1):19-25.
21. Burns KE, Duffett M, Kho ME, et al. A guide for the design and conduct of self-administered surveys of clinicians. CMA7 2008;179(3):245-52.

22. Rothmier JD, Lasley MV, Shapiro GG. Factors influencing parental consent in pediatric clinical research. Pediatrics 2003;111(5 Pt 1):1037-41.

23. Langley JM, Halperin SA, Mills EL, et al. Parental willingness to enter a child in a controlled vaccine trial. Clin Invest Med 1998;21(1):12-6.

24. Harris PA, Taylor R, Thielke R, et al. Research electronic data capture (REDCap) - a metadata-driven methodology and workflow process for providing translational research informatics support. 7 Biomed Inform 2009;42(2):377-81.

25. Warren DW, Jarvis A, LeBlanc L. Canadian paediatric triage and acuity scale: implementation guidelines for emergency departments. CFEM 2001;3(Suppl 4):S1-27.

26. Gill C, Ansermino MJ, Sanatani S, et al. Paediatric patient family engagement with clinical research at a tertiary care paediatric hospital. Paediatr Child Health 2014; 19(10):537-42. 